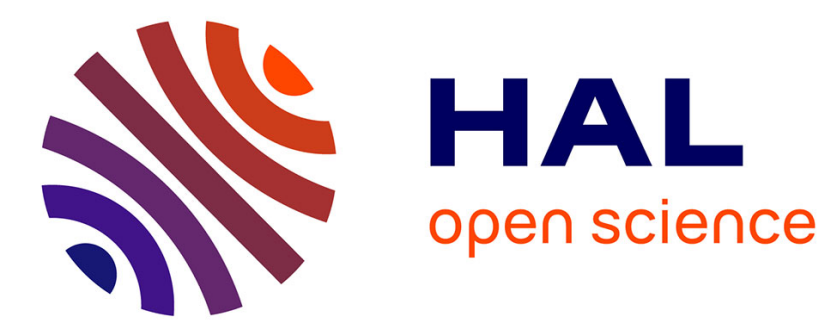

\title{
Effect of flow history on the structure of a non-polar polymer/clay nanocomposite model system
}

Christophe Mobuchon, Pierre Carreau, Marie-Claude Heuzey

\section{To cite this version:}

Christophe Mobuchon, Pierre Carreau, Marie-Claude Heuzey. Effect of flow history on the structure of a non-polar polymer/clay nanocomposite model system. Rheologica Acta, 2007, 46 (8), pp.1045-1056. 10.1007/s00397-007-0188-5 . hal-01006776

\section{HAL Id: hal-01006776 https://hal.science/hal-01006776}

Submitted on 3 Feb 2018

HAL is a multi-disciplinary open access archive for the deposit and dissemination of scientific research documents, whether they are published or not. The documents may come from teaching and research institutions in France or abroad, or from public or private research centers.
L'archive ouverte pluridisciplinaire HAL, est destinée au dépôt et à la diffusion de documents scientifiques de niveau recherche, publiés ou non, émanant des établissements d'enseignement et de recherche français ou étrangers, des laboratoires publics ou privés. 


\title{
Effect of flow history on the structure of a non-polar polymer/clay nanocomposite model system
}

\author{
Christophe Mobuchon, Pierre Carreau, Marie-Claude Heuzey
}

\author{
C. Mobuchon : P. J. Carreau : M.-C. Heuzey Center for \\ Applied Research on Polymers and Composites (CREPEC), \\ Chemical Engineering Department, \\ Ecole Polytechnique, \\ P.O. Box 6079, Stn Centre-Ville, \\ Montreal, QC, Canada H3C3A7 \\ e-mail:pcarreau@polymtl.ca
}

\begin{abstract}
The effect of flow history on the linear and nonlinear viscoelastic properties of non-polar polymer nanocomposites (PNCs) has been investigated by means of a suitable model system based on a Newtonian matrix. The structural recovery of this model suspension after cessation of different pre-shear rates was monitored by measuring its linear viscoelastic properties while its structural evolution under shear flow was followed by using stepwise changes in shear rate including flow reversal measurements. To assess the kinetics of the structural evolution at rest and under flow, empirical relations of stretched exponential form were used. It is shown that for different pre-shear rates, different equilibrium structures were reached at rest but with a similar kinetics of recovery. As a result, the low frequency behaviour was typical of solid-like or weak gel material, strongly dependent on the flow history. After any given shear rate under steady state, only one reversible equilibrium structure was reached after a kinetics that was dependent on the preshear history. Finally, typical flow reversal responses as observed for PNCs are reported and interpreted in light of the microstructure evolution under flow.
\end{abstract}

Keywords Polymeric nanocomposites · Layered silicate . Model suspension · Flow history · Linear viscoelasticity · Forward and reversal transient shear flows

\section{Introduction}

Layered silicates find widespread industrial applications such as rheological modifiers in paints, inks, emulsions or pigment suspensions, adsorbent in water treatment, and more recently as drug delivery carriers for controlled release of therapeutic agents and as nanoscale fillers for reinforcement of polymers (Patel et al. 2006). Polymer/layered silicate nanocomposites (PNCs) have attracted great interests since Okada et al. (1987) developed a nylon-based nanocomposite with significant improvements in tensile modulus and heat distortion with as little as 2 vol\% of layered silicate. Recent studies to extend a similar achievement to a wider range of polymer matrices, including vinyl and polyolefins, have also shown an enhancement of flexural, barrier and fire retardancy properties and unusual chemical and physical phenomena, such as highly anisotropic electrical conductivity and photoactivity when compared with conventional fillers (Ray and Okamoto 2003).

The layered silicates used in the synthesis of PNCs belong to the same structural family than the well-known clays mica and talc, i.e. 2:1 phyllosilicates (Grim 1968; Rossman and Carel 2002). The most commonly used is the montmorillonite for which the individual layers are stacked with relatively weak electrostatic forces facilitating the dispersion of the layers. The individual clay layers can be approximated by ellipsoidal tactoids about $1.2 \mathrm{~nm}$ thick, $320-400 \mathrm{~nm}$ long and $250 \mathrm{~nm}$ wide for the larger ones (Cadene et al. 2005).

The individual dispersion of these layers, i.e. their exfoliation, can lead to a large interfacial area in polymer matrix approaching $\mathrm{m}^{2} / \mathrm{mL}$ compared to $\mathrm{cm}^{2} / \mathrm{mL}$ for particles of micrometer dimensions (Krishnamoorti and Vaia 2002). This large interfacial interaction between the polymer matrix and the layered silicate explains the 
improved mechanical and physical properties over conventional polymer composites. Despite intensive research efforts, the exfoliation of inorganic-layered silicates remains a main challenge, especially in non-polar polymers. In the latter case, the incompatibility is overcome by using a coupling agent with organically modified layered silicates. Structurally, three different morphologies are achievable on the basis of the affinity between the polymer and the layered silicate: exfoliated nanocomposites as defined previously, intercalated nanocomposites, where the insertion of polymeric chains between the clay layers occurs but the stacking of layers is preserved, and finally conventional macrocomposites in the case of immiscible systems, when the polymer does not penetrate the stack of silicate layers.

To tailor PNCs with expected properties and to control their processing, a thorough understanding of PNC rheological behaviour with regards to the previously defined morphologies and their structural evolution is essential. In addition to the large interfacial area, the rheological behaviour is expected to be governed by two main features, i.e. the high aspect ratio of the clay layers and the effect of Brownian motion on the nanoparticles. The high aspect ratio of the clay layers, or high anisotropy, implies large excluded volumes, which results in clay-restricted motion at low volume fraction, corresponding to a concentrated regime. The concentrated regime is reached when $p \phi_{v} / \pi>>1$, with $p$ as the aspect ratio and $\varphi_{v}$ as the volume fraction of the clay particles (Lim and Park 2001). Actually, for a collection of oriented clay particles, the mean distance between the clay particles considered as discs with a thickness of $1.2 \mathrm{~nm}$ approaches $30 \mathrm{~nm}$ at a volume fraction of $4 \%$ compared with their lateral dimensions larger than $200 \mathrm{~nm}$. It is interesting to note that because of their high aspect ratio, a relative flexibility of the clay layers can also be observed (Morgan and Gilman 2003). Furthermore, because of their nanometric dimensions, these clay particles in suspension are subjected to Brownian motion, which tends to randomise their relative position and reorient the nanoparticles at rest. Under flow, the Brownian forces (and possibly other colloidal forces) are counterbalanced by the hydrodynamic forces. The relative balance between these two is expressed by the Peclet number, given by $P e=\dot{\gamma} / D_{\mathrm{r}}$, where $\gamma$ is the shear rate and $D_{\mathrm{r}}$ is the rotary diffusion coefficient. The rotary diffusion coefficient of the clay layers can be calculated as $D_{\mathrm{r}}=3 k_{B} T / 4 \eta d^{3}$ (Larson 1999; Ren et al. 2003) where $k_{B}$ is the Bolztmann constant, $T$ is the absolute temperature, $\eta$ is the viscosity of the matrix and $d$ is the particle diameter. The competition between the Brownian motion and the hydrodynamic forces leads to a complex reversible time-dependent rheological behaviour, which is characteristic of colloidal suspensions, i.e. a thixotropic behaviour related to changes occurring in the inner structure of the fluid such as spatial distribution and orientation (Barnes 1997).

Previous rheological studies of PNCs primarily focused on their linear rheological behaviour and the key results are reviewed by Krishnamoorti and Yurekli (2001). The most striking observation is the solid-like behaviour, i.e. $G^{\prime}$ and $G^{\prime \prime} \sim \omega^{0}$ at low silicate loadings (as low as $1.5 \mathrm{vol} \%$ as reported by Aubry et al. 2005). This non-terminal flow behaviour has been observed for exfoliated nanocomposites (Hoffmann et al. 2000; Koo et al. 2003; Krishnamoorti and Giannelis 1997; Li et al. 2003; Lim and Park 2001; Meincke et al. 2003; Wang et al. 2002). It has also been observed for intercalated PNCs by Galgali et al. (2001), Lim and Park (2001), Ren et al. (2000) and Solomon et al. (2001), for PNCs based on polar matrices by Aubry et al. (2005), Hsieh et al. (2004), Krishnamoorti and Giannelis (1997) and Lepoittevin et al. (2002) as well as for non-polar polymers (Hoffmann et al. 2000; Koo et al. 2003; Li et al. 2003; Lim and Park 2001; Meincke et al. 2003; Solomon et al. 2001; Wang et al. 2002). The non-terminal flow behaviour is attributed to the formation of a percolated three-dimensional network, which hinders the relaxation of the clay particles when subjected to small amplitude oscillatory shear (SAOS; Galgali et al. 2001; Mitchell and Krishnamoorti 2002; Ren et al. 2000). As outlined previously, the particle-to-particle distance shorter than their lateral dimensions prevents the free rotation of the particles and the stress relaxation. The relatively low silicate volume fraction ( $1.5 \mathrm{vol} \%$, Aubry et al. 2005) for which the percolation threshold is reached is strikingly different from the case of spheres ( $\sim 30 \mathrm{vol} \%$; Isichenko 1992; Ren et al. 2000; Wang et al. 2002) and is also a consequence of the high anisotropic nature of the clay particles. According to the small-angle X-ray scattering studies of Bafna et al. (2003), Galgali et al. (2004), Kojima et al. (1994, 1995), Lele et al. (2002), Medellin-Rodriguez et al. (2001) and Varlot et al. (2001), clay layers are oriented in shear flow with their major axis along the flow direction and their surface nearly oriented in the shear plane. The linear viscoelastic response after steady preshear flows is significantly weaker (at all frequencies) than those measured before pre-shear (Koo et al. 2003; Li et al. 2003). Similarly, application of a prolonged large amplitude oscillatory shear (LAOS) affects in the same way the subsequent linear viscoelastic response (Krishnamoorti and Giannelis 1997; Lim and Park 2001; Ren et al. 2000, 2003; Ren and Krishnamoorti 2003). The ability of LAOS to orient the clay layers, as observed for block copolymers (Gupta et al. 1996), has been confirmed by Ren et al. (2003) and Koo et al. (2003) while conducting ex-situ Xray measurements.

The previous studies underline the correlation between the linear viscoelastic properties of PNCs and the micro- 
structure induced by a well-defined preconditioning. Several outstanding issues are yet to be investigated such as the evolution of the rheological response and of the clay structure during preconditioning (not reported in any of the previous studies) and the effect of preconditioning on the non-linear viscoelastic properties. Moreover, previous investigations have been restricted to a few different experimental conditions. Only one shear rate was applied by Koo et al. (2003, $1 \mathrm{~s}^{-1}$ ) and by Li et al. (2003) while LAOS experiments have been limited to two sets of experimental conditions: a strain of 1.2 at a frequency of $1 \mathrm{rad} / \mathrm{s}$ (Krishnamoorti and Giannelis 1997; Lim and Park 2001; Ren et al. 2003) and a strain of 1.5 at $0.1 \mathrm{rad} / \mathrm{s}$ (Ren et al. 2003).

The kinetics of disorientation after LAOS preconditioning has been examined by Ren et al. (2003) using linear viscoelastic measurements for polystyrene and poly(isobutylene-co-p-methylstyrene)-based PNCs. They observed logarithmic increases with time of the storage modulus, which did not depend significantly on the dimensions of the silicate layers, temperature, viscoelasticity and molecular weight of the polymer matrix. They concluded from these results that the disorientation process was not governed by Brownian motion. Lele et al. (2002) have reported the relaxation of orientation for polypropylene-based PNCs after a steady pre-shear preconditioning using in situ X-ray diffraction (XRD) measurements. They confirmed the conclusion of Ren et al. (2003) because the relaxation time scale from rheo-XRD measurements was much faster than the expected Brownian relaxation time $\left(1 / D_{\mathrm{r}}\right)$. Instead, they suggested that the rapid relaxation of the nanoparticle orientation was driven by the stress relaxation of the polymer matrix chains. Solomon et al. (2001) also observed a relaxation faster in polypropylene-based PNCs than the one expected from Brownian motion. This was attributed to the attractive interactions between the clay tactoids in the quiescent structural evolution after a steady pre-shear. This last explanation was rejected by Lele et al. (2002) because they observed a relaxation time depending on the presence of a coupling agent ( $i$-PP/maleic anhydride copolymer). Actually, the uncompatibilised PNCs at a similar clay loading exhibited slower relaxation times than the compatibilised ones.

Solomon et al. (2001) investigated the extent of the relaxation by conducting reversal flow measurements. They monitored the stress growth upon start-up of steady-shear flow in the reverse direction after a first start-up at the same shear rate. A stress overshoot was only observed during the reverse flow when a rest time between the two consecutive experiments was sufficiently long. The reverse overshoot was explained by the re-orientation and the network structure built-up during rest time. The overshoot magnitude was found to increase with rest time but with time scales much shorter than expected from Brownian motion, leading Solomon et al. (2001) to the hypothesis that Brownian motion was not the driving force for the quiescent structural evolution.

Finally, fewer reports have been made on the non-linear viscoelastic properties of PNCs measured during the first start-up of steady-shear flow (Lee and Han 2003; Li et al. 2003; Solomon et al. 2001). The stress overshoot during the first start-up flow was found to increase with the applied shear rate (Li et al. 2003; Solomon et al. 2001) and the extent of clay exfoliation (Lee and Han 2003). The transient stress was found to scale with the strain, indicating that the Brownian motion did not significantly contribute to the stress response in the shear rate range investigated $\left(0.005-1 \mathrm{~s}^{-1}\right)$.

In the present study, the effect of flow history on the linear and non-linear viscoelastic properties of non-polar PNCs was carefully investigated by examining the rheological behaviour of a suitable model system based on a Newtonian matrix. At first, we present the structural recovery of this model suspension monitored by measuring the linear viscoelastic properties after cessation of different pre-shear rates. Afterwards, the structural evolution under shear flow conditions is reported for stepwise changes in shear rate including flow reversal measurements. To assess the kinetics of the structural evolution at rest and under flow, empirical relations of stretched exponential form are used.

\section{Experimental}

Materials and preparation methods

The layered-silicate selected for the model suspension was a montmorillonite, $\mathrm{M}_{x}\left(\mathrm{Al}_{2-y} \mathrm{Mg}_{y}\right) \mathrm{Si}_{4} \mathrm{O}_{10}(\mathrm{OH})_{2} \cdot \mathrm{nH}_{2} \mathrm{O}$, organically modified with a dimethyl dihydrogenated quaternary ammonium salt, $\mathrm{CH}_{3} \mathrm{CH}_{3} \mathrm{~N}^{+} \mathrm{HTHT}$, where $\mathrm{HT}$ is a hydrogenated tallow (Cloisite ${ }^{\circledR}$ 15A, Southern Clay Products). The specific gravity of this organophilic clay is 1.66 .

The clay was added at a volume fraction of $4 \%$ in a nonpolar Newtonian fluid consisting of a blend of two miscible polybutenes, $\mathrm{R}\left[\mathrm{CH}_{2} \mathrm{CCH}_{3} \mathrm{CH}_{3}\right]_{x}\left[\mathrm{CH}_{2}\right]_{y} \mathrm{R}$, of different molecular mass, respectively, $910 \mathrm{~g} / \mathrm{mol}$ (76.4 mass\%, Indopol $\mathrm{H} 100, \mathrm{BP})$ and $1,300 \mathrm{~g} / \mathrm{mol}$ (23.6 mass\%, Indopol H300, BP) with an overall viscosity of $28.5 \mathrm{~Pa} \mathrm{~s}$ at $25{ }^{\circ} \mathrm{C}$ and a density of $0.89 \mathrm{~g} / \mathrm{mL}$. Under flow, the clay particles dispersed in the polybutene are thus not subjected to electrostatic repulsion or attraction but only to van der Waals interactions, steric forces excluded volume effect, Brownian motion and hydrodynamic forces.

The model suspensions were prepared via ultrasonication, using pulses of $240 \mathrm{~W}$ during $1 \mathrm{~s}$, every $5 \mathrm{~s}$ at $60{ }^{\circ} \mathrm{C}$ for $60 \mathrm{~min}$ (Sonics \& Materials). This was followed by a 
rest time in a high vacuum oven at $60{ }^{\circ} \mathrm{C}$ to remove air bubbles before measurements. The duration of ultrasonication was found not to affect the degree of dispersion of the suspensions as measured by the amplitude of the dynamic storage modulus plateau, and the suspension was found to be very stable over long periods of time. Other methods of incorporating the nanoclay to the polybutene were observed to strongly affect the rheological properties. However, this will not be discussed here and will be the topic of another publication. After sonication, the initially cloudy dispersions became translucid and gel-like, indicating enhancement of the dispersion degree. To investigate further the clay dispersion in the polybutene, wide angle X-ray diffraction (WAXRD) was used. The data were collected using a Philips X'pert powder diffractometer with $\mathrm{CuK} \alpha(\lambda=1.54 \AA)$ radiation and an accelerating voltage of $50 \mathrm{kV} / 40 \mathrm{~mA}$. The step size and the scanning speed were $0.025^{\circ}$ and 2 s/step, respectively. While the observed gelation of the suspensions indicated exfoliation of the clay layers, their diffraction pattern (not shown here) still presented the characteristic $d_{001}$ basal reflection peak of Cloisite $15 \mathrm{~A}$. This peak is indicative of the presence of stacked clay layers as confirmed by transmission electron microscopy (TEM). Figure 1 shows a typical TEM micrograph of the model suspension under a large magnification. The TEM micrograph was taken from a 100-nm-thick ultracryomicrotomed section of the model suspension using an Ultracut E ultracryomicrotome (Reichert \& Jung) at $-80{ }^{\circ} \mathrm{C}$. Imaging was performed with a JEOL JEM-2000FX transmission electron microscope at an accelerating voltage of $80 \mathrm{kV}$. Both individual silicate layers and thin clay tactoids can be seen from the micrograph of Fig. 1. Therefore, clay exfoliation was not perfectly achieved, explaining the single diffraction peak observed in WAXRD. This non-homogeneous morphology is close to commonly observed dispersion states for non-polar polymer/clay nanocomposites (see for instance Li et al. 2003).

Finally, with a typical value of $d=320 \mathrm{~nm}$, the Peclet number is estimated to be between $10^{-1}$ and $10^{5}$ for shear rates ranging from $10^{-3}$ to $10 \mathrm{~s}^{-1}$. This suggests that the Brownian motion must play a key role in this shear rate range. To evaluate the Peclet number, the viscosity of our suspension at high shear rate, $\eta \approx 70 \mathrm{~Pa} \mathrm{~s}$ at $T=295 \mathrm{~K}$ (see Fig. 2a), was used rather than that of the matrix, to account for the fact that our suspension is highly concentrated (Moan et al. 2003).

\section{Rheometry}

All the rheological measurements were carried out using a stress-controlled rheometer (Physica MCR 501, Anton Paar), except for the stress relaxation measurements that were performed with a strain-controlled rheometer (ARES, Rheometric Scientific). All tests were done at $25^{\circ} \mathrm{C}$ using a

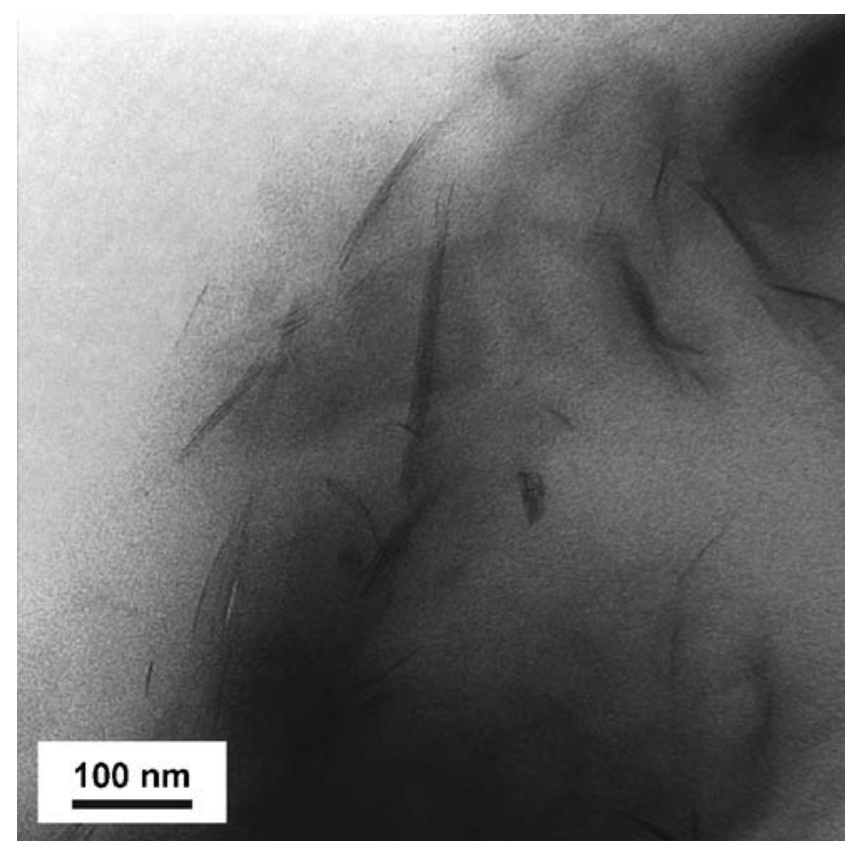

Fig. 1 TEM micrograph of the model suspension

cone-and-plate geometry with a radius of $50 \mathrm{~mm}$ and a cone angle of $0.04 \mathrm{rad}$. We assumed that the particle sizes were sufficiently small compared to the gap $(h)$ of the cone-andplate geometry (i.e. $d / h<0.1$ ). SAOS frequency sweep tests were conducted in the range of $0.628-628 \mathrm{rad} \mathrm{s}^{-1}$ at a fixed strain of 0.005 . For stress relaxation experiments, the ARES rheometer was preferentially used because its force-rebalanced torque system was more suitable for measuring the true sample response when the filters were bypassed to avoid electronic interferences from the instrument (Dullaert and Mewis 2005a, b; Mackay et al. 1992). The raw data from the ARES force-rebalanced transducer were sampled every $10^{-4} \mathrm{~s}$ with a 12-bit data acquisition card (DAQPAd$6020 \mathrm{E}$, National Instruments), and the data handling was performed using a LabVIEW routine (National Instruments). For the stepwise shear rate measurements using the MCR, the data were considered after a period of $0.04 \mathrm{~s}$, time required to reach the specified shear rate within an error of less than $2 \%$.

The absence of slip and wall effects for the model suspension have been ascertained using a parallel plate geometry with a radius of $25 \mathrm{~mm}$. The effect of the gap (varied from 0.2 to $1.4 \mathrm{~mm}$ ) and of the roughness of the geometry (smooth and modified with sandpaper: 220 grit, aluminium oxide) on the steady-shear measurements were found to be insignificant, less than the reproducibility of the data estimated to be within \pm 2 and $\pm 9 \%$ for shear rates of 25 and $0.001 \mathrm{~s}^{-1}$, respectively. For dynamic measurements, the standard deviation based upon five measurements carried out with fresh samples was estimated to be within $\pm 8 \%$.

To confer the same shear flow history at the beginning of each measurement, the suspensions were subjected to a 


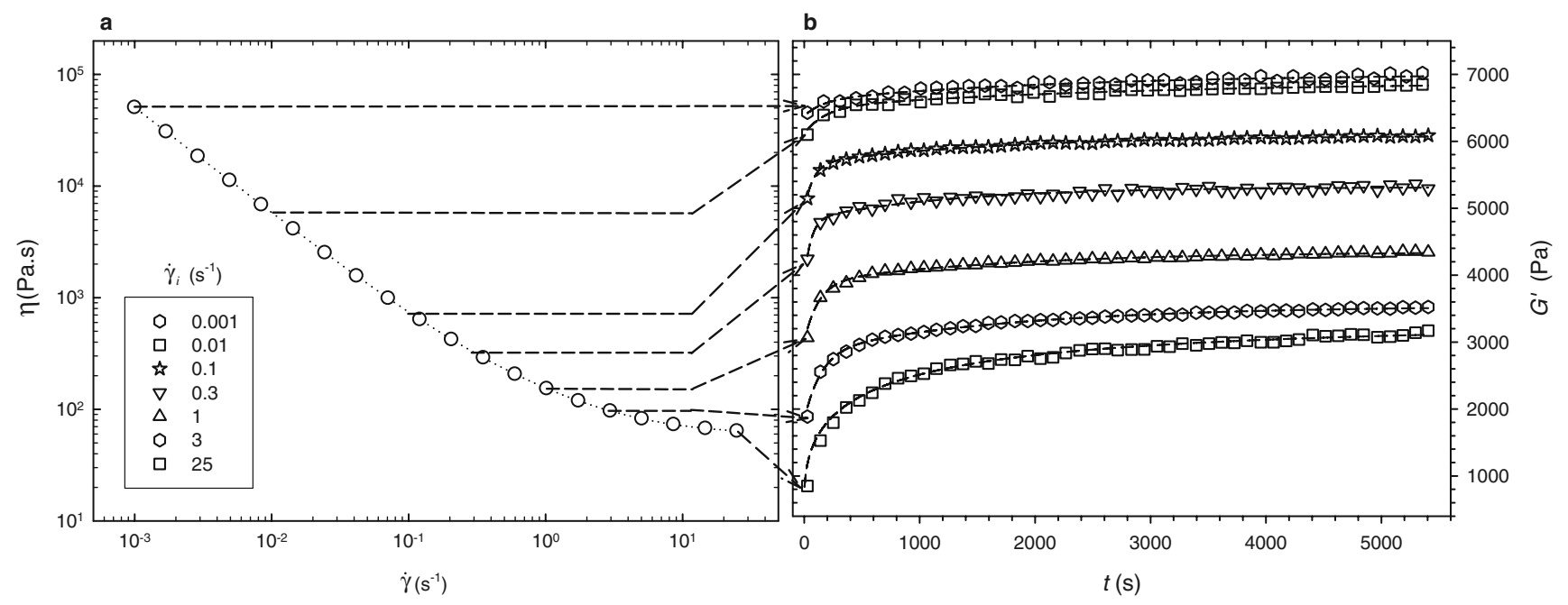

Fig. 2 Structure changes under preconditioning: a steady viscosity $\eta$ vs shear $\dot{\gamma}$ rate and $\mathbf{b}$ storage modulus $G^{\prime}$ vs time $t$ at a frequency of $125.6 \mathrm{rad} \mathrm{s}^{-1}$ upon cessation of the steady-state flow imposed in $\mathbf{a}$.

constant pre-shearing. Initially, various pre-shearing rates were tested to optimise the conditioning. While investigating the resulting structures using SAOS, strikingly different results were obtained. Figure 2a reports the steady-shear viscosity of the model suspension for tests carried out from 25 to $10^{-3} \mathrm{~s}^{-1}$. The behaviour is typical of a highly concentrated suspension, with a gel-like structure responsible for an unbounded viscosity (apparent yield stress) at low shear rates and a plateau viscosity at very high shear rates. Figure $2 \mathrm{~b}$ presents the evolution of the storage modulus $G^{\prime}$ at a frequency of $125.6 \mathrm{rad} \mathrm{s}^{-1}$ after each applied pre-shear rate shown in Fig. 2a, starting with the larger value of $25 \mathrm{~s}^{-1}$. Some structure build-up curves have been removed from Fig. $2 b$ for clarity. For the larger values of the initially applied shear rate, the storage modulus is shown to be very small and increases first rapidly, and then the growth rate appears to reach a constant value at longer times. After conditioning at a very small shear rate after an initial preshear at $25 \mathrm{~s}^{-1}$, the initial storage modulus is much larger, and the rate of increase with time is comparable to that observed at long times for tests carried out after a large initial shear rate. Although the rates of increase appear to be quite similar for long times, no equilibrium structure is reached after $5,000 \mathrm{~s}$, and the modulus for the test carried out after an applied shear rate of $10^{-3} \mathrm{~s}^{-1}$ is more than double that obtained after the applied shear rate of $25 \mathrm{~s}^{-1}$. Obviously, the resulting structures are highly dependent on the previous flow history. Note that the same structure development would be obtained if, after pre-shearing at $25 \mathrm{~s}^{-1}$, the second shearing would have been carried out at $10^{-3} \mathrm{~s}^{-1}$ instead of carrying the shear rate-decreasing ramp. However, the time required to reach steady state at that low shear rate would have been much longer. Actually, this strong dependence of the structure on flow history was the motivation of the work
Symbols indicate the values of the initial shear rate $\dot{\gamma}_{\mathrm{i}}$ of the steady shear flows; the solid lines represent best fits using Eq. 1

presented here, in which we investigate in depth the evolution of the structure at rest and under flow. In all subsequent measurements, the samples were pre-sheared at $25 \mathrm{~s}^{-1}$ until a steady state viscosity was observed to ensure a similar initial structure for all samples. After that preshearing, various rest times and/or flow conditions were imposed as discussed in the following sections.

\section{Results}

Structure build-up at rest

The results of Fig. $2 b$ can be used to evaluate the effect of the flow history on the clay structure build-up at rest. It is important to keep in mind that the storage modulus $G^{\prime}$ of the model suspension arises only from the clay structure because the matrix is inelastic, while both of them contribute to the loss modulus $G^{\prime \prime}$. Figure $2 \mathrm{~b}$ shows that $G^{\prime}$ grows from an initial value $G_{\mathrm{i}}^{\prime}$ to a time invariant value $G_{\infty}^{\prime}$ following an exponential form:

$G^{\prime}(t)=G_{i}^{\prime}+\left(G_{\infty}^{\prime}-G_{i}^{\prime}\right)\left(1-\exp \left[-\left(\frac{t}{\tau}\right)^{m}\right]\right)$

with $m$ as the stretching exponent and $\tau$ as the characteristic time. A similar trend was observed for $G^{\prime \prime}$, which was larger than $G^{\prime}$ at $125.6 \mathrm{rad} \mathrm{s}^{-1}$. The values of $G_{\mathrm{i}}^{\prime}$ and $G_{\infty}^{\prime}$ are shown in Fig. 3 to depend strongly on the initially applied shear rate $\dot{\gamma}_{\mathrm{i}}$. The stretching exponent $m(\approx 0.3)$ is nearly independent of the initial shear rate, and the characteristic time $\tau$ tends to a constant value ( $\approx 600 \mathrm{~s})$. This means that the kinetics of the build-up process at rest does not depend significantly on the flow history. However, the build-up 


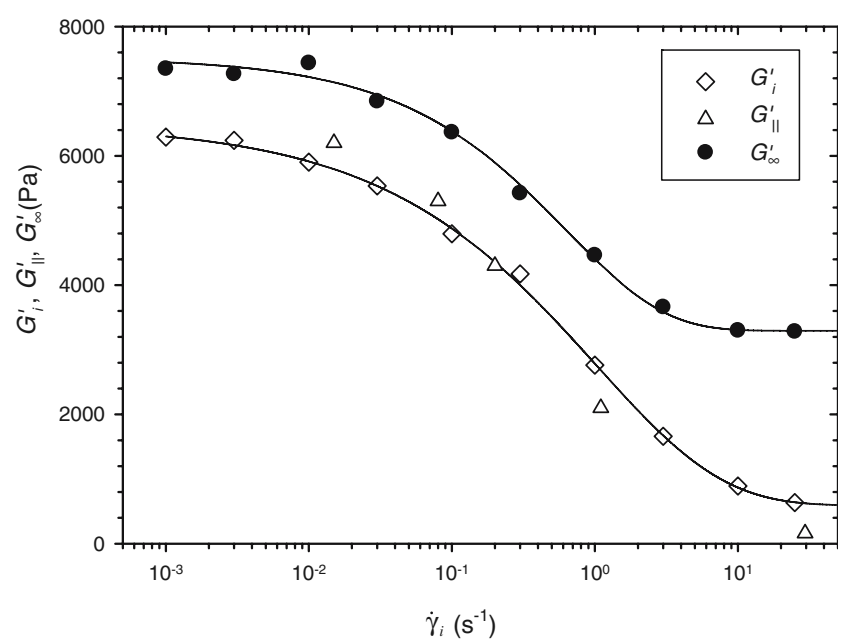

Fig. 3 Storage modulus parameters of Eq. 1 vs initial shear rate $\dot{\gamma}_{i}$ obtained by fitting the data shown in Fig. $2 \mathrm{~b}$

process leads to different equilibrium structures, as $G_{\infty}^{\prime}$ decreases from high to low plateau values for increasing $\gamma_{\mathrm{i}}$ from $10^{-1}$ to $7 \mathrm{~s}^{-1}$. The estimated equilibrium structure $G_{\infty}^{\prime}$ is quite different from that of the initial modulus $G_{\mathrm{i}}^{\prime}$, especially for tests carried out after high initial shear rates. It should be pointed out that the initial modulus $G_{\mathrm{i}}^{\prime}$ reported in Fig. 3 was obtained by extrapolating the experimental data of Fig. $2 \mathrm{~b}$ using Eq. 1 to time zero over a time period longer than the inverse of the imposed frequency. This extrapolated value may appear questionable because of complications arising from the stress relaxation of the sample and limitations of the MCR rheometer to impose an oscillatory shear flow during the stress relaxation. However, it is interesting to note that $G_{\mathrm{i}}^{\prime}$ is, within experimental error, the same as the storage modulus $G_{\|}^{\prime}$, measured at a frequency of $125.6 \mathrm{rad} \mathrm{s}^{-1}$ using parallel superposition of SAOS to steady-shear flow at $\dot{\gamma}_{\mathrm{i}}$. As expected, the storage modulus measured in parallel superposition characterises the structure of the suspension destroyed by steady-shear flow. However, as mentioned by Moldenaers and Mewis (1993) for measurements on polymeric liquid crystals, this superposition is nontrivial because of the fast viscoelastic response with respect to instrument limitations outlined above. After a large initial shear rate, the destroyed structure characterised by $G_{\mathrm{i}}^{\prime}$ leads to a considerably weaker final structure $\left(G_{\infty}^{\prime}\right)$ when compared to the structure obtained after a lower initial shear rate. Consequently, the equilibrium structure build-up at rest, i.e. with the Brownian motion as the main driving force, strongly depends on the flow history. The Brownian character of the build-up process is suggested by the time scale to reach the final structure, which is comparable to the rotational relaxation time of an individual clay layer $\left(\left(1 / D_{\mathrm{r}} \approx 10^{3} \mathrm{~s}\right)\right)$. To our knowledge, only Jogun and Zukoski (1996) have reported a similar dependence of $G_{\infty}^{\prime}$ on the shear flow history for dense kaolin suspensions, but information on $G_{\mathrm{i}}^{\prime}$, characteristic of the initial structure after steady-shear flow, has not been presented.

An explanation for the behaviour depicted in Fig. 3 may be provided by the large excluded volume of the clay particles in the suspension. It results in a geometrically restricted (Brownian) motion of the nanoparticles. As mentioned above, at a volume fraction of $4 \%$, the distance between well-dispersed clay particles is shorter than their lateral dimensions. As a result, the hydrodynamic forces play a double role. Firstly, as expected for any given $\dot{\gamma}_{\mathrm{i}}, G_{\mathrm{i}}^{\prime}$ is always lower than $G_{\infty}^{\prime}$; that is, the structure under flow is always less developed than that of the pseudo-equilibrium value reflecting the competition between the breakdown because of the hydrodynamic forces and the build-up induced by Brownian motion. It is quite evident that the structure is destroyed more and more as the applied shear rate is increased, and hence $G_{\mathrm{i}}^{\prime}$ decreases with increasing $\dot{\gamma}_{\mathrm{i}}$. Secondly, one would expect the equilibrium value for $G_{\infty}^{\prime}$ to be unique; therefore, the decreasing value of $G_{\infty}^{\prime}$ with increasing $\dot{\gamma}_{\mathrm{i}}$ is difficult to explain. Note that $G_{\mathrm{i}}^{\prime}$ after a test at low shear rate (smaller than $0.6 \mathrm{~s}^{-1}$ ) can be larger than the pseudo-equilibrium $G_{\infty}^{\prime}$ obtained after a large initial shear rate. For tests carried out at shear rates below $0.6 \mathrm{~s}^{-1}$, the structure build-up is controlled not only by the Brownian motion but by small hydrodynamic forces required to overcome the effects of the large excluded volume of the particles.

Figure 4 reports the storage modulus as a function of frequency for the model suspension measured after different initial shear rates, themselves preceded by a preshearing at $25 \mathrm{~s}^{-1}$. These values, obtained after a 5,400-s rest time, are close to those of $G_{\infty}^{\prime}$ calculated by fitting the storage modulus as a function of time (Eq. 1). For small initial shear rates, a non-terminal flow behaviour is observed, characteristics of a weak gel, but the suspension becomes more liquid-like as the initial shear rate is increased. Finally,

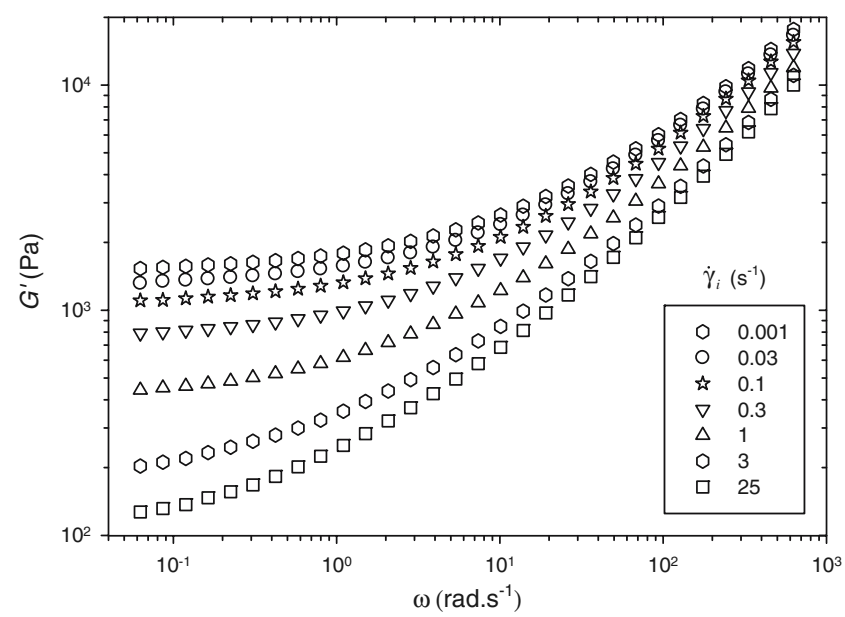

Fig. $4 G^{\prime}$ vs $\omega$ measured after steady-shear flow at $\dot{\gamma}_{\mathrm{i}}$ after a shear rate at $25 \mathrm{~s}^{-1}$ and rest time of $5,400 \mathrm{~s}$ 
the modulus at the lowest applied frequency $G_{0}^{\prime}$ follows the same trend as that of $G_{\infty}^{\prime}$ shown in Fig. 3.

In the light of the previous results, it is obvious that the shear flow history of PNCs need to be controlled if one wishes to draw some conclusions about the particle dispersion or volume fraction threshold, based on the lowfrequency dependency of $G^{\prime}$.

\section{Structure build-up under flow}

To assess the effect of the flow history on the structure build-up under flow, the transient shear stress $\sigma^{-}$resulting from a sudden change from a high to a low shear rate was measured (the structure breakdown is investigated in the next section with sudden changes from an initial shear rate lower than the final one). This process is important because it may shed light on the previously reported observations, mainly the structure build-up observed in Fig. $2 \mathrm{~b}$ after preshearing at $25 \mathrm{~s}^{-1}$ down to very low shear rates. Typical transient responses for the model suspension to a stepwise reduction in shear rate from different $\dot{\gamma}_{\mathrm{i}}$ to a final value $\dot{\gamma}_{\mathrm{f}}$ of $0.1 \mathrm{~s}^{-1}$ are illustrated in Fig. 5. Similar trends were observed for final shear rates ranging from 0.01 to $1 \mathrm{~s}^{-1}$. The fast decrease in $\sigma^{-}$at short times, corresponding to the viscoelastic response of the suspension, is followed by a monotonic increase up to an equilibrium shear stress independent of $\dot{\gamma}_{\mathrm{i}}$. If the structure of this suspension under steady-shear flow is shown to be independent of the shear flow history, the structure build-up under flow strongly depends on the history, in contrast to the kinetics of the build-up at rest, which does not depend significantly on the flow history, as discussed above. The observations reported in Fig. 5 are very similar to those presented by Dullaert and Mewis (2005a, b) for fumed silica suspensions. They modified the so-called stretched exponential model to take

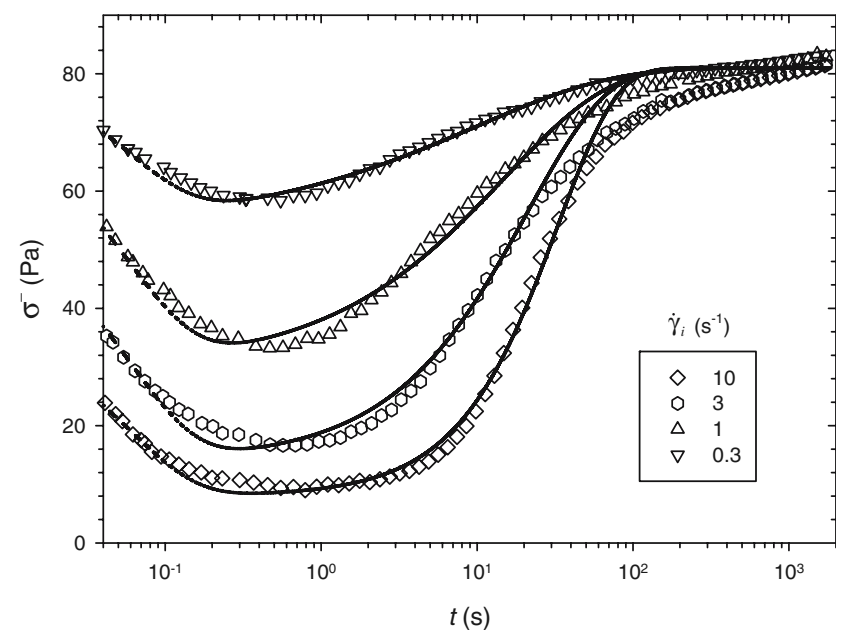

Fig. $5 \sigma^{-}$vs $t$ after a stepwise reduction in shear rate to a final value $\dot{\gamma}_{\mathrm{f}}$ of $0.1 \mathrm{~s}^{-1}$. The solid lines represent best fits using Eq. 2 into account the initial viscoelastic response. The empirical equation is:

$$
\begin{aligned}
\sigma(t)= & \sigma_{1}\left(\exp \left(-\frac{t}{\tau_{1}}\right)\right) \\
& +\sigma_{2}\left(1-\exp \left[-\left(\frac{t}{\tau_{2}}\right)^{m}\right]\right)+\sigma_{3}
\end{aligned}
$$

where $\sigma_{1}$ and $\sigma_{2}+\sigma_{3}$ represent the steady stress for the initial and final shear rate, respectively. The first and second terms on the right-hand side, respectively, describe the initial viscoelastic and thixotropic responses. The fits using this equation are shown by solid lines in Fig. 5, but the parameters are not reported here. While the characteristic time $\tau$ and the stretching exponent $m$ of Eq. 1 for the structure build-up at rest are almost independent of the initial shear rate, clear dependences are observed for the thixotropic characteristic time $\tau_{2}$ and $m$ of Eq. 2 for the structure build-up under flow. The characteristic time $\tau_{2}$ follows a power-law behaviour with indexes equal to approximately -0.7 and 0.4 for the final shear rate $\dot{\gamma}_{\mathrm{f}}$ and initial shear rate $\dot{\gamma}_{\mathrm{i}}$ dependencies, respectively. The build-up process is mainly strain-controlled as $\tau_{2}$ is nearly inversely proportional to the final shear rate. A similar power-law dependence on $\dot{\gamma}_{\mathrm{f}}$ has been observed by Dullaert and Mewis (2005a, b) for fumed silica suspensions. As a lower $\tau_{2}$ induces a faster build-up, the previous powerlaw indexes reflect that a faster equilibrium structure is reached starting from a more developed initial structure (low initial shear rate) and finishing with a less developed structure (large final shear rate). We note that the structure of the suspension subjected to changes in shear rate as illustrated in Fig. 5 is represented by the storage modulus measured in SAOS as reported in Fig. $2 b$ and described by Eq. 1 .

The initial viscoelastic responses shown in Fig. 5 and characterised by $\sigma_{1}$ in Eq. 2 are not reliable because the filtering technique of the MCR rheometer is susceptible to influence the measurements (Dullaert and Mewis 2005a, b; Mackay et al. 1992). Instead, the fast viscoelastic relaxation upon cessation of flow was investigated using the ARES rheometer according to a suitable procedure as reported by Mackay et al. (1992) and more recently by Dullaert and Mewis (2005a, b). Figure 6 presents the shear stress relaxation function $\sigma^{-}$of the nanoclay suspension upon cessation of steady-shear flow for different initial shear rates $\dot{\gamma}_{i}$. The first $28 \mathrm{~ms}$ of the data are ignored because of limitations of the instrument as beforehand revealed by the non-instantaneous decay of the stress observed for a Newtonian oil (not shown). Above $28 \mathrm{~ms}$ and up to $60 \mathrm{~ms}$, the log-linear extrapolation of $\sigma^{-}$to time zero (time of cessation of the steady-shear flow) yields the elastic component of the steady-shear stress as the viscous stress contribution dissipates instantaneously. The curves are well described by the first term of Eq. 2 with a characteristic time 


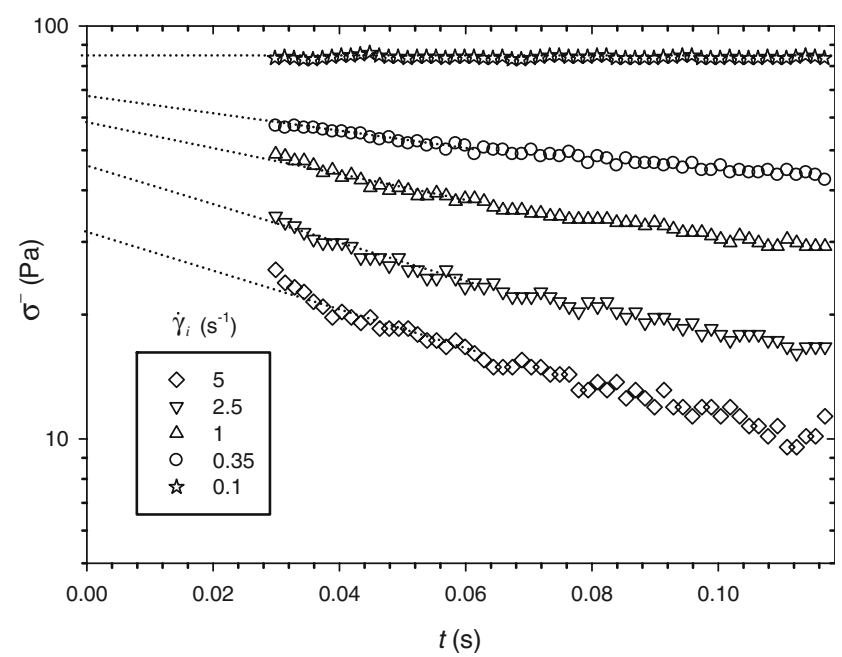

Fig. $6 \sigma^{-}$vs $t$ upon cessation of flow after steady state for different initial shear rates $\dot{\gamma}_{\mathrm{i}}$. The solid lines represent log-linear regressions

$\tau_{1}$, which is a function of the initial shear rate. This elastic contribution is related to an apparent yield stress caused by the particle structure and is discussed further below.

The elastic $\left(\sigma_{\mathrm{e}}\right)$ and viscous $\left(\sigma_{\mathrm{v}}\right)$ contributions, along with the total steady stress $(\sigma)$ of the nanoclay suspension, are presented in Fig. 7. The steady-shear data were obtained during a decreasing shear rate ramp using a measurement time of $200 \mathrm{~s}$ (no differences were noticeable for longer measurement times). Actually, the use of a decreasing shear rate allowed reaching the equilibrium state faster because the thixotropic characteristic time $\tau_{2}$ decreases when $\dot{\gamma}_{i}$ approaches $\dot{\gamma}_{\mathrm{f}}$ as already discussed above. The steady-shear behaviour is well described by the Bingham equation:

$\sigma=\sigma_{0}+\mu_{0} \dot{\gamma}$

where $\sigma_{0}$ and $\mu_{0}$ are the apparent yield stress and the highshear-rate viscosity of the suspension, respectively. The apparent yield stress determined from the best fit of the experimental data is $70 \mathrm{~Pa}$. The elastic contribution $\sigma_{\mathrm{e}}$ in Fig. 7 increases with decreasing shear rate and represents the apparent yield stress at low shear rate (below $0.1 \mathrm{~s}^{-1}$ ). On the other hand, the viscous contribution increases with shear rate to become larger than $\sigma_{\mathrm{e}}$ above a critical shear rate of $0.6 \mathrm{~s}^{-1}$, leading to a purely viscous behaviour for shear rates larger than $7 \mathrm{~s}^{-1}$. The critical shear rate of $0.6 \mathrm{~s}^{-1}$ is relevant because, as outlined before, the structure build-up is induced not only by Brownian motion but by small hydrodynamic forces. The structural and hydrodynamic contributions to the flow curve of fumed silica suspensions follow similar trends, as previously shown by Dullaert and Mewis (2005a, b).

Structure breakdown

A similar procedure for characterizing the structure breakdown under flow was used by measuring the transient stress

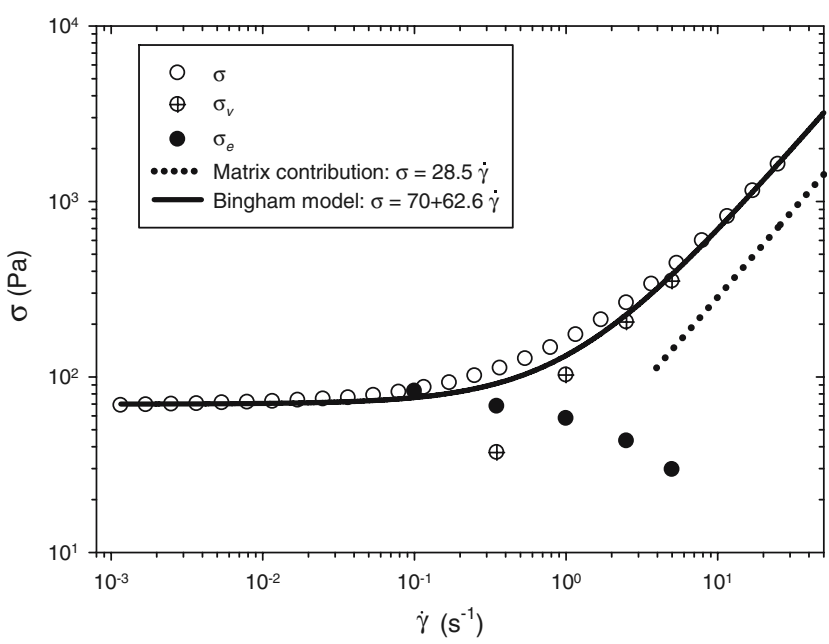

Fig. 7 Elastic $\left(\sigma_{\mathrm{e}}\right)$ and viscous $\left(\sigma_{\mathrm{v}}\right)$ contributions to the total steady stress $\sigma$ vs $\dot{\gamma}$. Dotted and solid lines represent the matrix contribution and the best fit using Eq. 3, respectively

$\sigma^{+}$for stepwise increases in shear rate. Figure 8 reports the transient shear stress data of the model suspension as a function of strain for jumps from an initial shear rate $\dot{\gamma}_{i}$ of $10^{-2} \mathrm{~s}^{-1}$ to different larger final shear rates $\dot{\gamma}_{\mathrm{i}}$. Additional experiments have been carried out from different initial shear rates to a final shear rate of $1 \mathrm{~s}^{-1}$, but the results are not presented here. All the results of Fig. 8 display large overshoots located at a critical strain $\dot{\gamma}_{\mathrm{i}}$ before reaching a steady-state value $\sigma_{\infty}^{+}$. Starting from the same initial structure (same initial shear rate) the increasing overshoot with increasing final shear rate reflects both the elastic response of the initial structure $\left(\sigma_{\mathrm{e}}\right.$ in Fig. 7) and the breakdown and rearrangement of the structure under flow. The rearrangement is mainly strain controlled because $\gamma_{\sigma_{\max }^{+}}$ is nearly independent of $\dot{\gamma}_{\mathrm{f}}$. The rearrangement may include anisotropy of the microstructure and/or orientation of the

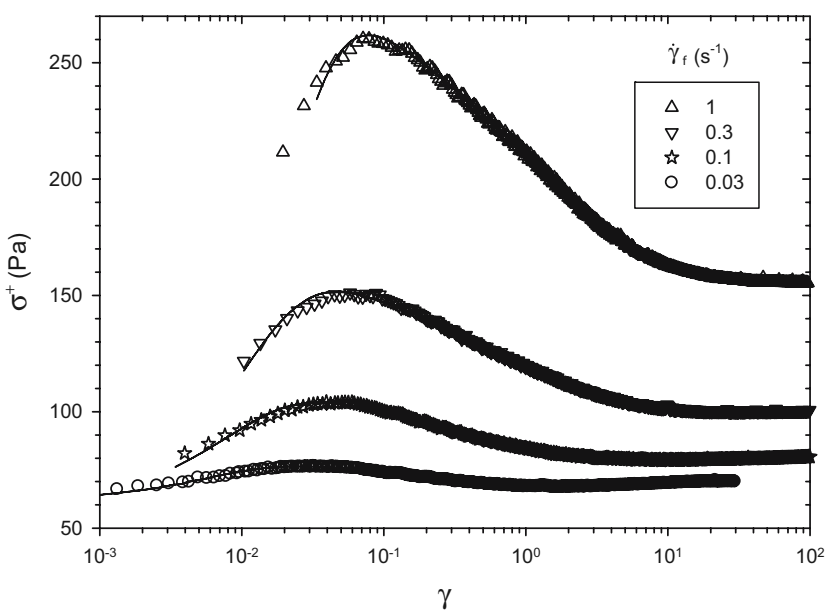

Fig. $8 \sigma^{+}$vs $\gamma$ for stepwise increases in shear rate from an initial $\dot{\gamma}_{\mathrm{i}}=0.01 \mathrm{~s}^{-1}$ to different shear rates. The solid lines are the best fits using Eq. 4 
nanoparticles under flow, as observed for fibre suspensions by Ausias et al. (1992). However, the anisotropy and the orientation under transient flow still need to be experimentally confirmed using optical rheometry. Similar mechanisms have been proposed by Pignon et al. (1998) for suspensions of laponite in water.

The time-dependent changes in stresses depicted in Fig. 8 can be described using a similar empirical equation than that used for the build-up curves (Eq. 2). This equation (Dullaert and Mewis 2005a, b) is:

$$
\begin{aligned}
\sigma(t)= & \sigma_{1}\left(1-\exp \left(-\frac{t}{\tau_{1}}\right)\right) \\
& -\sigma_{2}\left(1-\exp \left[-\left(\frac{t}{\tau_{2}}\right)^{m}\right]\right)+\sigma_{3}
\end{aligned}
$$

The fits are shown by the solid lines in Fig. 8. The parameters are not reported, but the characteristic time $\tau_{2}$ follows the same power-law dependence on the final shear rate (index equals to -0.7 ) as obtained from build-up experiments. Hence, the structure breakdown as well as the structure build-up are mainly strain controlled. The stretching exponent $m$ and $\tau_{2}$ dependences on the initial shear rate are also found to be similar to those observed from build-up measurements (power-law index close to 0.4).

Stepwise increases in shear rate induce breakdown of the initial structure characterised by $G_{\mathrm{i}}^{\prime}$ (Fig. 3) and shown to develop at rest to different final structures characterised by $G_{\infty}^{\prime}$. The stress growth behaviour of the developed structures is illustrated in Fig. 9 for an applied shear rate of $1 \mathrm{~s}^{-1}$, preceded by a preconditioning at $25 \mathrm{~s}^{-1}$ down to a shear rate of $\dot{\gamma}_{i}$ and after a rest time of 5,400 s. As expected, the shear stress displays a larger overshoot as the initial structure is more developed, i.e. for low $\dot{\gamma}_{i}$. The overshoot $\sigma_{\max }^{+}$as a function of the initial shear rate is shown in Fig. 9b to follow exactly the same trend as $G_{\infty}^{\prime}$ (Fig. 3), with a transition over the same $\dot{\gamma}_{i}$ range, with a high plateau at the lowest $\dot{\gamma}_{\mathrm{i}}$ and a low one at high $\dot{\gamma}_{\mathrm{i}}$. The opposite tendency is shown by the critical strain $\gamma_{\sigma_{\max }^{+}}$, which goes from a lower plateau at the lowest $\dot{\gamma}_{\mathrm{i}}$ to a higher plateau for large $\dot{\gamma}_{\mathrm{i}}$, suggesting that the more developed structure breaks down at a lower strain and is therefore more fragile. Critical strain data obtained for stress growth experiments carried out at the same shear rate as the initial one, $\dot{\gamma}_{i}$, after a rest time of 5,400 s follow the same trend (closed circles in Fig. 9b).

Figure 10 presents the effect of the rest time and of the applied shear rate on the overshoots for stress growth experiments carried out at the same final shear rate $\dot{\gamma}_{\mathrm{f}}$ as the initial $\dot{\gamma}_{\mathrm{i}}$. In this case, the stress overshoot can be entirely attributed to the breakdown and rearrangement of the structure developed during the rest time. The reduced
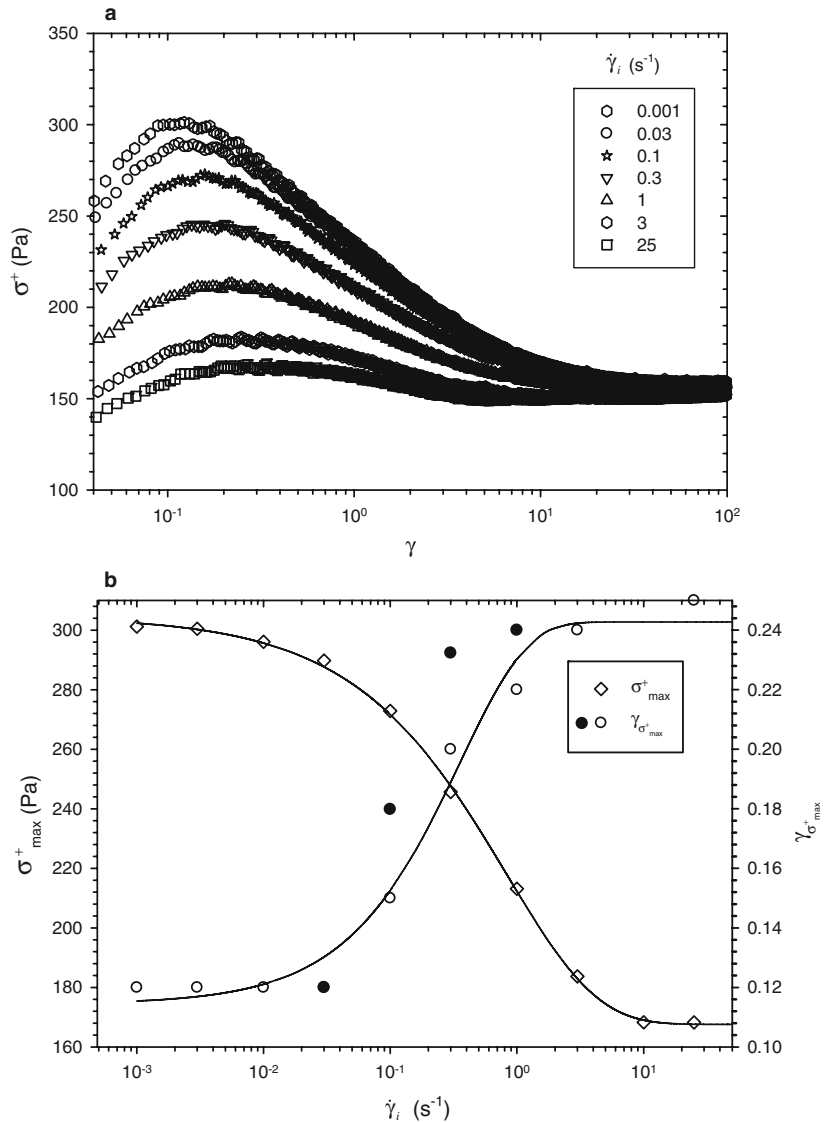

Fig. 9 Stress growth behaviour for the model suspension. a $\sigma^{+}$vs $\gamma$ for stress growth experiments carried out at $1 \mathrm{~s}^{-1}$ after a rest time of $5,400 \mathrm{~s}$, after a preconditioning at $25 \mathrm{~s}^{-1}$ and down to a shear rate of $\dot{\gamma}_{\mathrm{i}} ; \mathbf{b} \sigma_{\max }^{+}$and $\gamma_{\sigma_{\max }^{+}}$vs $\dot{\gamma}_{\mathrm{i}}$ after a rest time of 5,400 s (open circles for $\gamma_{\mathrm{f}}=1 \mathrm{~s}^{-1}$ and closed symbols for $\dot{\gamma}_{\mathrm{f}}=\dot{\gamma}_{\mathrm{i}}$ ). The lines are drawn to guide the eyes

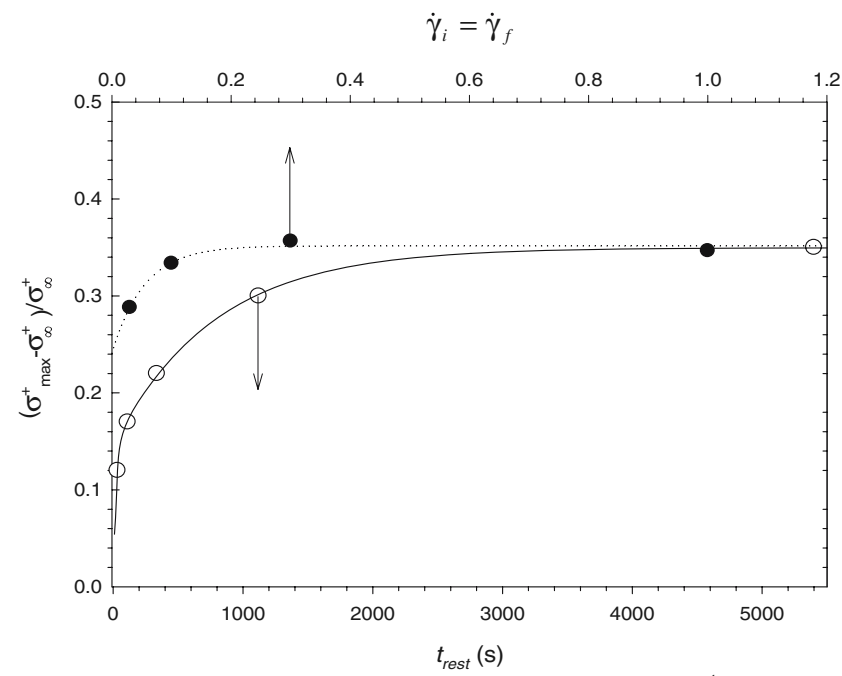

Fig. 10 Reduced stress overshoot $\left(\sigma_{\max }^{+}-\sigma_{\infty}^{+}\right) / \sigma_{\infty}^{+}$vs $t_{\text {rest }}\left(\dot{\gamma}_{\mathrm{f}}=\dot{\gamma}_{\mathrm{i}}=\right.$ $\left.0.3 \mathrm{~s}^{-1}\right)$ and vs shear rate $\gamma_{\mathrm{f}}=\dot{\gamma}_{\mathrm{i}}$ after a rest time of four consecutive experiments carried out at the same shear rate 
overshoot function $\left(\sigma_{\max }^{+}-\sigma_{\infty}^{+}\right) / \sigma_{\infty}^{+}$from measurements carried out at $0.3 \mathrm{~s}^{-1}$ is shown to increase with rest time following a stretched exponential form as observed previously for the recovery of the storage modulus $G^{\prime}$ (Fig. 2b). The reduced overshoot is observed to increase slightly with increasing shear rate confirming the findings of $\mathrm{Li}$ et al. (2003) and Solomon et al. (2001).

\section{Flow reversal}

To get an insight of the anisotropy effect of the structure, flow reversal measurements have been performed. Results of consecutive stress growth experiments without rest time are shown in Fig. 11 for three imposed shear rates. When the initial pre-shearing is applied in the same (clockwise, $\mathrm{CW}$ ) direction as the following applied shear rate, steady state is rapidly reached as shown by constant stress values in the figure (open symbols). However, if the direction of the pre-shearing is in the counter-clockwise direction whereas the subsequent shear rate is applied in the $\mathrm{CW}$ direction, the shear stress (closed symbols) goes to very low and even negative values before increasing monotonously to finally reach the same steady-state value $\sigma_{\infty}^{+}$. At the lowest imposed shear rate of $0.03 \mathrm{~s}^{-1}$ for the flow reversal case, $\sigma^{+}$is first negative up to a deformation of 0.06 and is the result of the relaxation of the structure developed during the previous shear (opposite direction); afterwards, the positive value of $\sigma^{+}$is indicative of the stretching and build-up of the new structure. The $\sigma^{+}$value at time zero is approximately equal to the elastic contribution $\sigma_{\mathrm{e}}$ shown in Fig. 7. At larger shear rates, the initial viscoelastic response is only partially visible because of the smaller elastic contribution and the accessible time scale of the rheometer. Even at the largest shear rate, $\sigma^{+}$does not display a reverse

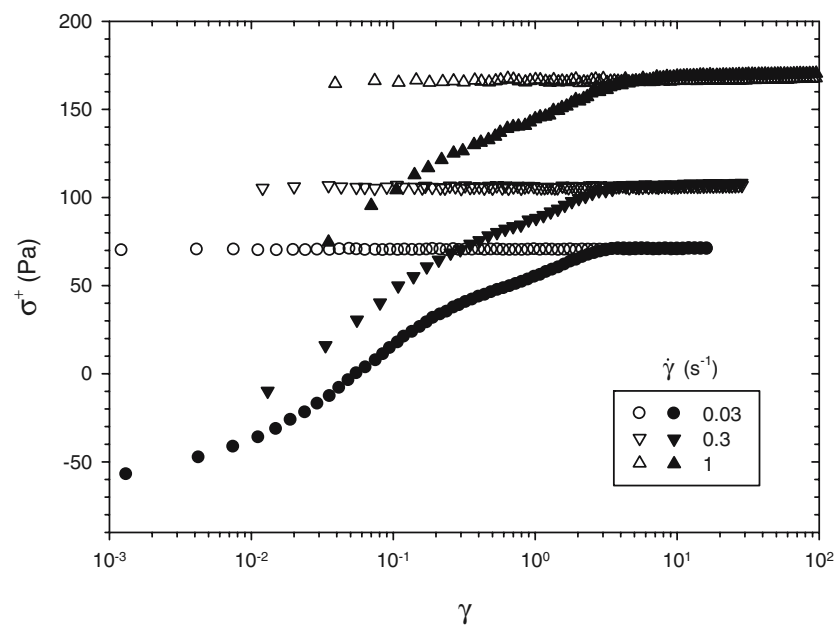

Fig. $11 \sigma^{+}$vs $\gamma$ for consecutive stress growth experiments after a preshearing in the same $(\mathrm{CW})$ direction and in the opposite $(C C W)$ direction overshoot as observed by Sepehr et al. (2004) for concentrated short fibre suspensions and attributed to the tumbling of fibres.

The interpretation of the previous transient viscoelastic response is extended by investigating the reverse flows done after a rest time of $5,400 \mathrm{~s}$, and the results are reported in Fig. 12. The reduced transient shear stress $\sigma^{+} / \sigma_{\infty}^{+}$starts from a low value because the structure relaxes during the allowed rest time. Then, $\sigma^{+} / \sigma_{\infty}^{+}$displays a peculiar behaviour revealing a first small overshoot or shoulder and then a second overshoot at a larger strain. The first overshoot or shoulder is located at a strain value similar to those of the overshoots observed during the stress growth experiments of Figs. 8 and 9. The first overshoot, clearly visible at high shear rates, must be related to the viscoelastic response and breakdown of the initial structure developed at rest. The second overshoot, seen even for low shear rates, takes place at a strain more than one decade larger than the first one. It is indicative of the structure rearrangement and build-up. By comparing the trend depicted in Fig. 12 with that of Fig. 9a at $\dot{\gamma}=1 \mathrm{~s}^{-1}$, it is obvious that the structure remains strongly anisotropic even after a long rest time. This behaviour outlines again the restricted Brownian motion, as discussed before. Our results confirm the importance of the Brownian motion on the transient behaviour, in contrast to the conclusions of Solomon et al. (2001), Lele et al. (2002) and Ren et al. (2003). We finally note that Solomon et al. (2001) reported single overshoots for the reverse flow experiments. However, the peculiar behaviour shown in Fig. 12 may not be visible in their results because they used a linear scale for the strain. In addition, the viscoelastic nature of their polymer matrix could have affected the transient responses of their nanocomposites.

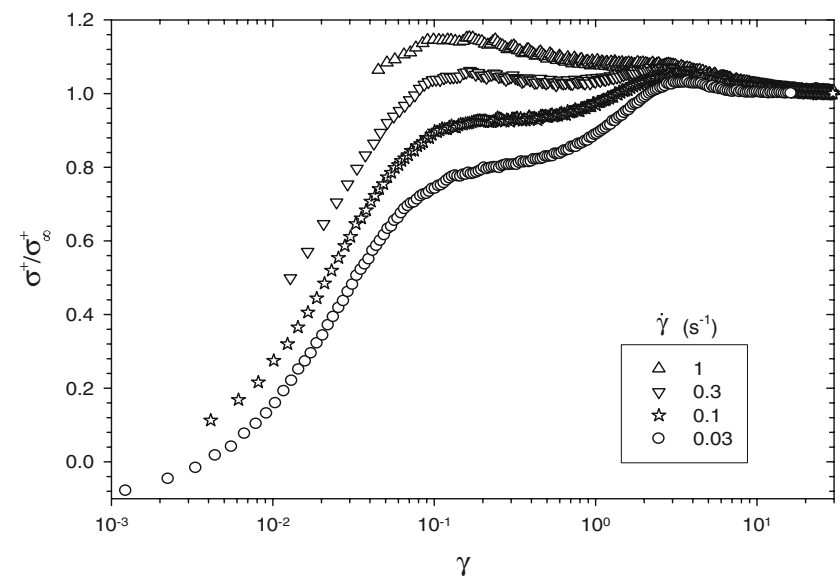

Fig. $12 \sigma^{+} \sigma_{\infty}^{+}$vs $\gamma$ for stress growth experiments after a preshearing in the opposite $(\mathrm{CCW})$ direction and a rest time of 5,400 s 


\section{Concluding remarks}

The linear and non-linear viscoelastic properties of a model suspension for non-polar polymer/clay nanocomposites have been investigated taking into account the flow history. The time evolution of the viscoelastic properties reported only arise from the structural changes of the clay structure because this model suspension is based on a Newtonian matrix.

Upon cessation of steady-shear flows, different equilibrium structures are reached, which strongly depend on the pre-shear rate. A lower pre-shear rate leads to the development of a stronger equilibrium structure. It follows that the non-terminal behaviour of this model suspension is more solid-like as the pre-shear rate decreases. The existence of these different pseudo-equilibrium structures has been attributed to the large excluded volume of the clay particles. The structure build-up is controlled not only by the Brownian motion but by small hydrodynamic forces required to overcome the effects of the large excluded volume of the particles.

The build-up as well as the breakdown of the clay structure under flow follow a similar kinetics described by empirical relations of stretched exponential form, which depends on the flow history, as observed for nanoparticles of fumed silica by Dullaert and Mewis $(2005 \mathrm{a}, \mathrm{b})$. The amplitude of the stress overshoots observed during breakdown measurements increases with rest time and with decreasing pre-shear rate, i.e. following the same trend as the structure described by the storage modulus measured in SAOS.

Finally, overshoots are observed for reverse stress growth experiments but only after a long rest time, confirming the findings of $\mathrm{Li}$ et al. (2003) and Solomon et al. (2001). Our flow reversal results suggest a strong anisotropy of the shear-induced clay structure, which persists even after a long rest time, outlining the restricted Brownian motion. This flow reversal response as well as the other transient responses could be elucidated by following the overall orientation of the clay structure using rheo-optical methods. These will be reported in a subsequent publication.

Acknowledgements The authors wish to thank Dr. Hojatolla Vali and Dr. Kelly Sears, from McGill University, for their precious help with the TEM experiments. Southern Clay Products kindly provided materials used in this study. One of the authors (CM) is thankful to Alcan for a scholarship. Finally, financial support from NSERC (Natural Science and Engineering Research Council of Canada) and from FQRNT (Fonds Québécois de Recherche en Nature et Technologies) is gratefully acknowledged.

\section{References}

Aubry T, Razafinimaro T, Mederic P (2005) Rheological investigation of the melt state elastic and yield properties of a polyamide- 12 layered silicate nanocomposite. J Rheol 49:425-440
Ausias G, Agassant JF, Vincent M, Lafleur PG, Lavoie PA, Carreau PJ (1992) Rheology of short glass fiber reinforced polypropylene. J Rheol 36:525-543

Bafna A, Beaucage G, Mirabella F, Mehta S (2003) 3D hierarchical orientation in polymer-clay nanocomposite films. Polymer 44 (4):1103-1115

Barnes HA (1997) Thixotropy—a review. J Non-Newton Fluid Mech $70(1-2): 1-33$

Cadene A, Durand-Vidal S, Turq P, Brendle J (2005) Study of individual $\mathrm{Na}$-montmorillonite particles size, morphology, and apparent charge. J Colloid Interface Sci 285(2):719-730

Dullaert K, Mewis J (2005a) Stress jumps on weakly flocculated dispersions: steady state and transient results. J Colloid Interface Sci 287(2):542-551

Dullaert K, Mewis J (2005b) Thixotropy: build-up and breakdown curves during flow. J Rheol 49(6):1213-1230

Galgali G, Ramesh C, Lele A (2001) Rheological study on the kinetics of hybrid formation in polypropylene nanocomposites. Macromolecules 34(4):852-858

Galgali G, Agarwal S, Lele A (2004) Effect of clay orientation on the tensile modulus of polypropylene-nanoclay composites. Polymer 45(17):6059-6069

Grim RE (1968) Clay mineralogy. McGraw-Hill New York

Gupta VK, Krishnamoorti R, Chen ZR, Kornfield JA, Smith SD, Satkowski MM, Grothaus JT (1996) Dynamics of shear alignment in a lamellar diblock copolymer: interplay of frequency, strain amplitude, and temperature. Macromolecules 29 (3):875-884

Hoffmann B, Dietrich C, Thomann R, Friedrich C, Mülhaupt R (2000) Morphology and rheology of polystyrene nanocomposites based upon organoclay. Macromol Rapid Commun 21(1):57-61

Hsieh AJ, Moy P, Beyer FL, Madison P, Napadensky E, Ren J, Krishnamoorti R (2004) Mechanical response and rheological properties of polycarbonate layered-silicate nanocomposites. Polym Eng Sci 44(5):825-837

Isichenko MB (1992) Percolation, statistical topography, and transport in random media. Rev Mod Phys 64:961-1043

Jogun S, Zukoski CF (1996) Rheology of dense suspensions of platelike particles. J Rheol 40(6):1211-1232

Kojima Y, Usuki A, Kawasumi M, Okada A, Kurauchi T, Kamigaito O, Kaji K (1994) Fine structure of nylon-6-clay hybrid. J Polym Sci B Polym Phys 32(4):625-630

Kojima Y, Usuki A, Kawasumi M, Okada A, Kurauchi T, Kamigaito O, Kaji K (1995) Novel preferred orientation in injection-molded nylon 6-clay hybrid. J Polym Sci B Polym Phys 33(7):1039

Koo CM, Kim MJ, Choi MH, Kim SO, Chung IJ (2003) Mechanical and rheological properties of the maleated polypropylene-layered silicate nanocomposites with different morphology. J Appl Polym Sci 88(6):1526-1535

Krishnamoorti R, Giannelis EP (1997) Rheology of end-tethered polymer layered silicate nanocomposites. Macromolecules 30 (14):4097-4102

Krishnamoorti R, Vaia RA (2002) Polymer nanocomposites: synthesis, characterization, and modeling. American Chemical Society, Washington

Krishnamoorti R, Yurekli K (2001) Rheology of polymer layered silicate nanocomposites. Curr Opin Colloid Interface Sci 6:464-470

Larson RG (1999) The structure and rheology of complex fluid. Oxford Univ. Press, New York

Lee KM, Han CD (2003) Effect of hydrogen bonding on the rheology of polycarbonate/organoclay nanocomposites. Polymer 44 (16):4573-4588

Lele A, Mackley M, Ramesh C, Galgali G (2002) In situ rheo-X-ray investigation of flow-induced orientation in layered silicatesyndiotactic polypropylene nanocomposite melt. J Rheol 46 (5):1091-1110 
Lepoittevin B, Devalckenaere M, Pantoustier N, Alexandre M, Kubies D, Calberg C, Jerome R, Dubois P (2002) Poly (e-caprolactone)/ clay nanocomposites prepared by melt intercalation: mechanical, thermal and rheological properties. Polymer 43(14):4017-4023

Li J, Zhou C, Wang G, Zhao D (2003) Study on rheological behavior of polypropylene/clay nanocomposites. J Appl Polym Sci 89 (13):3609-3617

Lim YT, Park OO (2001) Phase morphology and rheological behavior of polymer/layered silicate nanocomposites. Rheol Acta 40 (3):220-229

Mackay ME, Liang CH, Halley PJ (1992) Instrument effects on stress jump measurements. Rheol Acta 31(5):481-489

Medellin-Rodriguez FJ, Burger C, Hsiao BS, Chu B, Vaia R, Phillips S (2001) Time-resolved shear behavior of end-tethered Nylon 6clay nanocomposites followed by non-isothermal crystallization. Polymer 42(21):9015-9023

Meincke O, Hoffmann B, Dietrich C, Friedrich C (2003) Viscoelastic properties of polystyrene nanocomposites based on layered silicates. Macromol Chem Phys 204(5-6):823-830

Mitchell CA, Krishnamoorti R (2002) Rheological properties of diblock copolymer/layered-silicate nanocomposites. J Polym Sci B Polym Phys 40(14):1434-1443

Moan M, Aubry T, Bossard F (2003) Nonlinear behavior of very concentrated suspensions of plate-like kaolin particles in shear flow. J Rheol 47(6):1493-1504

Moldenaers P, Mewis J (1993) On the nature of viscoelasticity in polymeric liquid crystals. J Rheol 37(2):367-380

Morgan AB, Gilman JW (2003) Characterization of polymer-layered silicate (clay) nanocomposites by transmission electron microscopy and X-ray diffraction: a comparative study. J Appl Polym Sci 87(8):1329-1338

Okada A, Kawasumi M, Kurauchi T, Kamigaito O (1987) Synthesis and characterization of a nylon 6-clay hybrid. Polymer Preprints 28(2):447-448
Patel HA, Somani RS, Bajaj HC, Jasra RV (2006) Nanoclays for polymer nanocomposites, paints, inks, greases and cosmetics formulations, drug delivery vehicle and waste water treatment. Bull Mater Sci 29(2):133-145

Pignon F, Magnin A, Piau J-M (1998) Thixotropic behavior of clay dispersions: combinations of scattering and rheometric techniques. J Rheol 42:1349-1373

Ray SS, Okamoto M (2003) Polymer/layered silicate nanocomposites: a review from preparation to processing. Prog Polym Sci (Oxford) 28(11):1539-1641

Ren J, Krishnamoorti R (2003) Nonlinear viscoelastic properties of layered-silicate-based intercalated nanocomposites. Macromolecules 36(12):4443-4451

Ren J, Silva AS, Krishnamoorti R (2000) Linear viscoelasticity of disordered polystyrene-polyisoprene block copolymer based layered-silicate nanocomposites. Macromolecules 33(10):3739-3746

Ren J, Casanueva BF, Mitchell CA, Krishnamoorti R (2003) Disorientation kinetics of aligned polymer layered silicate nanocomposites. Macromolecules 36(11):4188-4194

Rossman FG, Carel JvO (2002) Colloid and surface properties of clays and related minerals. Marcel Dekker, New York

Sepehr M, Carreau PJ, Moan M, Ausias G (2004) Rheological properties of short fiber model suspensions. J Rheol 48:1023-1048

Solomon MJ, Almusallam AS, Seefeldt KF, Somwangthanaroj A, Varadan P (2001) Rheology of polypropylene/clay hybrid materials. Macromolecules 34(6):1864-1872

Varlot K, Reynaud E, Kloppfer MH, Vigier G, Varlet J (2001) Clayreinforced polyamide: preferential orientation of the montmorillonite sheets and the polyamide crystalline lamellae. J Polym Sci B Polym Phys 39(12):1360-1370

Wang KH, Choi MH, Koo CM, Xu M, Chung IJ, Jang MC, Choi SW, Song HH (2002) Morphology and physical properties of polyethylene/silicate nanocomposite prepared by melt intercalation. J Polym Sci B Polym Phys 40(14):1454-1463 